\title{
A ORELHA DE VAN GOGH: ROSIE E A ALTERNATIVA CIBORGUE EM "OS JETSONS"
}

\author{
João Luiz Peçanha Couto* \\ Universidade Federal Fluminense
}

\begin{abstract}
Resumo: Desprovidos de sua história, e vendo-a ser resgatada somente a partir da segunda metade do XX por conta do crescimento dos movimentos dos direitos das minorias, tanto mulheres quanto afro-americanos (e outras minorias esquematicamente não tratadas aqui) ainda encontram dificuldades e demandam esforços de compreensão para atuarem e se situarem de modo politicamente ativo na pós-modernidade. Quando algo ou alguém concentra aqueles memoriais de exclusão (mulher e negra), acrescidos de uma não-humanidade, pode ser considerado exemplarmente um "outro" extremo. Rosie encarnaria, portanto, um inconsciente norte-americano idealizador do migrante terceiromundista: um "outro" sem texto, sem fala, sem história ou cultura. Nesse sentido, sua ontologia está intimamente ligada à sua inserção política relativa àquela sociedade - subalterna (SPIVAK, 1988), periférica e alternativa. Ao mesmo tempo aguilhoada simbolicamente a um passado escravocrata e a um presente de preconceitos latentes [a imagem da Black Mammy (KOWALSKI, 2009) é sintomática dessa trajetória e igualmente será aqui tratada] e a dívidas sociais não pagas, aponta para um futuro possível de convergências alternativas, tanto raciais e éticas quanto (bio) políticas. Seu poder e sua fraqueza dividem o mesmo espaço. Assim como as literaturas entendidas como periféricas ou de fronteira constantemente geram excessos em que a geografia se funde e se conflitua com a ontologia, com as subjetividades postas em xeque, tendo o devir histórico como pano de fundo, poderemos compreender que Rosie figura como um tipo de anti-Barbie mecatrônica. Assim, a partir da personagem Rosie, a doméstica-robô da série televisiva Os Jetsons, o artigo apresenta reflexões sobre os embates do sujeito periférico (porque não-masculino, não-branco, não-culto e não-humano) inserido na modernidade. Ao articular conceitos como os de ciborgue e subalternidade, e estereótipos como o da black Mammy, buscará entrever a presença de uma contradiscursividade hegemônica encarnada por Rosie, biotipicamente identificada com o padrão negroide e
\end{abstract}

\section{(i) $(9)$}

BY No ND Esta obra está licenciada sob uma Licença Creative Commons.

\footnotetext{
* Doutorando em Literatura Comparada (UFF), Mestre em Literatura (Estudos Comparados) pela Universidade de São Paulo (USP) e licenciado em Letras (Português e Inglês). Tem experiência em pesquisa e docência nas áreas de Literatura, Língua Portuguesa e Metodologia Científica. Foi professor de Língua Portuguesa na Educação Básica e é professor de Português e de Metodologia Científica no Ensino Superior - Faculdades Integradas Vianna Junior. Membro dos Grupos de Pesquisa “Aprendizagem em Rede - GRUPAR”, da UFJF, e "Identidades em trânsito: estéticas transnacionais", da Universidade Federal Fluminense (UFF). Autor de livros de literatura, dentre eles "Satie manda lembranças". Seu texto teatral "O pacote" recebeu prêmio nacional de dramaturgia pela Fundação Cultural da Bahia. Pesquisador, atua sobretudo nos seguintes temas: literaturas contemporâneas periféricas, modernidades alternativas pós-coloniais, literatura africana em língua portuguesa, espaços precários da pós-modernidade, filosofia e cinema em diálogo com a literatura. E-mail: joaoluizpecanhacouto@gmail.com.
} 
compreendida como desprovida do direito a uma história nacional, a um mito fundador e a uma forma de narrar o próprio passado. Desse ponto de vista, Rosie emerge como representante das modernidades alternativas presentes no seio do projeto de modernidade.

Palavras-chave: Contradiscursividade. Modernidades alternativas. Ciborgue. Black Mammy.

Introdução - Não há tempo que volte, amor: o projeto de modernidade e suas consequências

Edward Said assinala que uma das características do mundo contemporâneo reside no fato de ter produzido mais desterritorializações que em qualquer outra época histórica (SAID, 2011, p. 332). Tais desterros foram, em sua maioria, derivados de conflitos póscoloniais, o que gerou uma mesma desterritorialização da geografia íntima do sujeito pósmoderno, além de um estado de fluidez, de superposições e de inesperados entrelaçamentos de dessemelhanças, muitas vezes destronando as culturas ditas hegemônicas em nome de um crescimento, quem sabe uma apropriação (indébita?). Para Sônia Torres, o resultado desse reordenamento cultural "é o surgimento das chamadas culturas periféricas dentro do espaço que se convencionou denominar "centro"” (TORRES, 2001, p. 11). Portanto, as "subculturas", aquelas entendidas como culturas de fronteira / periféricas, e seu resultante mais atomizado, o sujeito pós-moderno, igualmente resultante desse despertencimento preliminar, são vistos beirando a semelhança com os fenômenos tumorizantes da biologia, pois são eles/as que, a partir de dentro, paulatinamente ressignificam todo o sistema hegemônico.

Desse modo, podemos compreender o fenômeno globalizante como "caracterizado pela multiplicidade das modernidades, e as teorias críticas pós-coloniais fornecem pistas para a compreensão de como tal se processa" (ASHCROFT, 2009, p. 81): é o terceiro mundo, com seus códigos e representações prenhes de tensão e de excessos (TORRES, 2001, p. 36), que implode a lógica da antiga metrópole.

Tais contradiscursos da modernidade não postulam, entretanto, uma "pureza" oposicional. Seus sujeitos "carregam em si as experiências históricas de diáspora (representando as raízes), trazendo-as para o novo espaço ocupado sem, contudo, demonstrar um desejo de retorno ao lar cultural" (TORRES, 2001, p. 117). Tais discursos e sujeitos entrecruzantes, portanto, acabam por se transnacionalizarem, o que lhes permite romper o binarismo ancestral "minoria X maioria". Isso faz com que deem novo significado ao sentimento de pertencimento, que emerge como transcendendo as fronteiras geográficas e transformando conceitos de nação, identidade e comunidade (TORRES, 2001, p. 118).

Segundo a mesma autora, sua fala não se contamina do discurso hegemônico contra o qual, em princípio, se move, pois sua verdade está no fato de não se inserirem como solução 
final, mas suporem ambiguidades: no mesmo movimento, são lei e subversão, invenção e controle, distopia e utopia (TORRES, 2001, p. 116). Essas ambiguidades assinalam uma substituição importante e decisiva, ao fazerem ser desmentidos os discursos puristas das minorias.

Entretanto, tais invasões/apropriações não ocorreram sem uma consequente reafirmação do discurso hegemônico, que tentava desqualificar aqueles movimentos. A proposta deste texto situa-se no encontro desses dois trajetos. Assim, Rosie, a doméstica-robô de Os Jetsons, emerge encravada naquela marmórea matriz W.A.S.P. ${ }^{1}$ (papai, mamãe, filha e filho Jetson), uma representante do seu contrário: Rosie não é humana, não é ser vivo (não totalmente, pelo menos, como veremos), não é branca e, pelo que sabemos, jamais revelou qualquer pendor metafísico.

O verso da moeda de Rosie igualmente lhe dá poderes, desde que a enxerguemos como atriz da ação tumorizante das culturas compósitas ou das modernidades alternativas. A partir desta constatação, miremos Rosie como representação, mesmo que reducionista, transubstanciada no estereótipo da black Mammy.

\section{Um estereótipo para chamar de seu: a anti-Barbie mecatrônica}

\section{If you don't care what folks says about dis family I does!} (Mammy, em Go with the winds)

Jennifer Kowalski (2009) lembra que, para Milan Kundera, a luta do homem contra o poder é a luta da memória contra o esquecimento. A frase assinala o descompasso existente entre aqueles atores que determinam quem ou o que é ignorado ou perpetuado pela história. Concorre para esta leitura Edward Said (SAID, 2011), que propõe que se transfigure o olhar histórico, permitindo que nele seja inserido o ponto de vista de seus "perdedores", a saber, os espaços e personagens da chamada periferia - os dejetos da modernidade ocidental (BAUMAN, 2005). Sobre esses atores ignorados e inaceitáveis - pois denunciam potências defeituosas da exclusão do processo modernizante ocidental - recaem estereótipos de classe, raça, gênero e sexualidade bastante úteis para a manutenção daquele discurso hegemônico.

A história oficial norte-americana criou tais estereótipos, que ainda persistem, apesar de esforços em contrário (KOWALSKI, 2009). Um dos mais persistentes e longevos é o da black Mammy, cuja voz é entrevista na fala epigrafada da personagem de Gone with the winds e cuja imagem deixa entrever certo esforço de enquadramento daquele tipo social na versão aceitável da história norte-americana: é a modernidade ajustando dessemelhanças para que se

\footnotetext{
${ }^{1}$ White Anglo-Saxon Protestant.
} 
adequem aos padrões sociais e culturais por ela mesma postulados desde seis séculos. A mítica personagem é pintada em cores de lealdade servil à sua senhora (Dona Scarlett), estendida a toda família O’Hara.

Tal “essencialização representacional” (CLIFFORD, 1992, p. 100) acaba por confinar aquele Outro numa espécie de "congelamento metonímico", ou seja, cristalizando determinadas características do Outro (seja ele periférico, negro, mulher, homossexual ou não humano), eu consigo representá-lo parcialmente e, por isso, contê-lo em características que o fazem, para mim, um Outro-objeto, dessubjetivando-o.

Em Os Jetsons, Rosie igualmente apresenta-se leal e servil - uma lealdade "feliz" que, além de negar historicamente sua condição ancestral escrava, distorce a luta empreendida por este "outro" (de raça e gênero, se formos agora, por força de conceituação esquemática, deixar de lado seu expediente não-humano). Rosie, tanto quanto o estereótipo sobre o qual foi erigida a personagem, exemplifica como a sociedade a transforma em "fato dado" (KOWALSKI, 2009): a distância temporal auxilia a dispersar suas significações servilistas historicamente datadas, naturalizando sua condição subalterna.

O que nos interessa, portanto, é o amplamente conhecido estereótipo da black Mammy, tratado por Kowalski e construído para, no extremo, nublar sua característica de origem escravocrata e amenizar sua condição verdadeira: um "outro" social absoluto. Negra, mulher e desprovida materialmente, a imagem da black Mammy foi incorporada a um quase memorial afetivo da criança norte-americana até meados do século $\mathrm{XX}$, quando os movimentos pelos direitos das minorias (negros, latinos, mulheres) se fizeram notar, sobretudo quando centralizados em personagens públicos fundamentais, como o foi Martin Luther King para os afro-americanos. Entretanto, aquela imagem mítica sulista norteamericana tem se modificado ao longo do tempo, tornando-se um estereótipo a sustentar interesses econômicos.

Em Os Jetsons, Rosie traz exemplarmente a imagem da black Mammy, incluindo neste travestimento grande parte das características verificadas por Kowalski no estereótipo. Dessa forma, Rosie tem ancas largas, braços fortes e roliços: aspectos que, longe de ressaltar sua feminilidade, caricaturam-na. Essa feminilidade exagerada ressalta a comicidade do tipo, gerando críticas jocosas - sobretudo raciais e de gênero - além de impossibilitar qualquer aproximação que venha a engendrar contato físico ou emocional entre a matriz patroa e a serva leal. Jennifer Kowalski acerta ao afirmar que o corpo da black Mammy é um tendão que liga os músculos do escravo afro-americano às estruturas de poder da aristocracia branca e 
sulista norte-americana (KOWALSKI, 2009). Nesse sentido, sua humanidade está restrita aos gestos afetivos dirigidos às crianças, filhas dos patrões, cuja manutenção e criação ficam a seu cargo.

Kowalski ainda assinala que é menos importante a verdade ou falsidade sobre a qual o estereótipo da black Mammy foi erigido; nesse sentido, importa mais a percepção de sua ação preventiva, que dificulta/impede a produção de novos significados para a história a ser contada - e, portanto, para a narrativa que sobreviverá ao tempo (KOWALSKI, 2009). Dessa forma, o "outro" (subalterno, periférico) é forçado a lidar com a história - não a história que ele reconhece como narrativa de si, mas aquela inscrita "dele", "para ele" ou "a seu respeito"jamais "por ele". Assim, o subalterno é alijado da escrita de sua história, pois a memória, à débito da história, igualmente seleciona aquilo que será mantido ou esquecido, o que acaba por nos fazer retornar a Edward Said e seu reconhecimento de que a história deveria também ser narrada por quem perdeu o jogo.

Assim, o estereótipo, acrescido de um falar grosseiro e comicamente petulante, acaba por masculinizar as ações e, sobretudo, o corpo da "outra" (mulher, negra e, no caso de Rosie, não-humana), figurando corporalmente a mulher afro-americana como a antítese da beleza feminina (branca, espartilhada).

Tal jogo ajuda a manter simbolicamente a black Mammy na periferia da sociedade, limitando seu acesso a seus recursos e instituições (KOWALSKI, 2009). A função do estereótipo, portanto, cumpre-se plenamente: a romantização das relações de poder que nos lembra vagamente as gentilezas entre senhor e escravos supostas por Gilberto Freyre (FREYRE, 2003) e mascaram crueldades perpetradas em nome da manutenção daquela estrutura; a desvalorização da voz daquele outro, que acumula "outros" em si: feminino, nãocurvilíneo, não branco e, no caso específico de Rosie (repito-me), não humana. Todo esse memorial de exclusões simbólicas ajuda a simplificar / reduzir e descontextualizar ontológica e politicamente aquele ser sobre o qual recai o estereótipo da black Mammy. Sua ausência de história, porque igualmente ausente de narrativa própria, porque igualmente despossuído existencial e economicamente, acaba por não só corroborar, como fazer ser tacitamente incorporada e perpetuada sua própria opressão.

Vimos, portanto, que Rosie admite aproximação com a imagem da black Mammy. Passo seguinte: pinçada uma das características da black Mammy (sua subalternidade), questionar até que ponto a voz deste subalterno pode franca e abertamente ser ouvida como 
propriedade original - ou se o copyright da fala do outro periférico acaba por não pertencer, de fato, a ele próprio. Vejamos.

\section{Ken ai tók, ma'am?}

No artigo Can the subaltern speaks, Gayatri C. Spivak investiga o sujeito do Ocidente e sua relação com seu Outro - não europeu, não branco e, por vezes, não cristão, argumentando que o Ocidente manifesta um desejo em "manter o sujeito do Ocidente, ou o Ocidente como sujeito" (SPIVAK, 1988, p. 24). O argumento fundamental do artigo questiona: "Do outro lado da divisão internacional do trabalho, dentro $e$ fora do circuito da violência epistêmica ${ }^{2}$ da lei e da educação imperialista [...] pode o subalterno falar?" (SPIVAK, 1988, p. 25).

Seu conceito de sujeito-efeito nos permitirá chegar a uma conclusão metodologicamente trágica porque conceitualmente cruel: o sujeito subalterno, o sujeito periférico, o Outro constitui-se como efeito do discurso dominante. Xeque-mate: eu, como “outro" político, econômico e social, permaneço calado; entretanto, quando falo, ou nas vezes em que ouso falar, mesmo que inconscientemente, ao assumir minha posição de outro daquela sociedade hegemônica, sou aquele "outro" por imposição conceitual e metodológica do mesmo que me assinalou como pária, condenando-me à marginalidade através da eternidade da história. Dessa forma, qualquer investida no sentido de conceituar o chamado "sujeito subalterno" esbarra preliminarmente na gênese do seu próprio esforço intelectual, uma vez que o Outro é outro porque foi criado por quem primeiramente se apropriou do discurso acadêmico (o Ocidente), responsável por nomear e classificar o mundo (ocidental) e as coisas.

\footnotetext{
Embora a história da Europa como Sujeito seja narrada pela lei, pela economia política e pela ideologia do Ocidente, esse Sujeito oculto alega não ter "nenhuma determinação geopolítica". Assim, a tão difundida crítica ao sujeito soberano realmente inaugura um Sujeito. (SPIVAK, 1988, p. 24)
}

Entretanto, se num primeiro momento a caracterização do sujeito-efeito sugere um tênue abalo na soberania do sujeito hegemônico europeu, igualmente o camufla e protege.

O presumido esforço da "inserção" de um Outro em "minha casa" traduz-se, no extremo, na manutenção da distância entre mim e o Outro: ele continua "outro", pois sua subjetivação estará sempre associada à minha aceitação. Torna-se, assim, impensável se prescindir do conceito de ideologia, tão caro aos marxistas, já que aquele discurso vem dela embebido e "desuterado".

\footnotetext{
${ }^{2}$ Cf. Foucault.
} 
Nesse sentido, é reiterada a pressuposição de Rosie como um Outro (extremo, porque feminino, porque periférico, porque não-humano) admitido (pensemos bem no significado do termo) no coração de uma típica família W.A.S.P. A discussão seguinte aponta para as fronteiras desta alteridade: o que difere o outro do um não se assenta apenas em aspectos social ou culturalmente determinados, permitindo tangenciamentos, no limite, junto à biologia, à robótica e à (bio) política.

\title{
Ciborgue: uma alternativa ontológica
}

\author{
Uma parte de mim \\ é todo mundo \\ outra parte é ninguém \\ poço sem fundo \\ (Traduzir-se, Ferreira Gullar)
}

Vejamos se, relacionando-a a outras minorias etnocentricamente afastadas do "centro" norte-americano de aceitação social, o conceito de ciborgue (HARAWAY, 2009) poderá ser aplicado a Rosie, ambiguamente entendida como dispositivo e ser, e por isso representando a questão do não-humano, o Outro, o animal: sua exclusão é representada por sua forma humana/não-humana (máquina, ciborgue, robô). Como reforço, é interessante pontuar que Janet Jetson, a filha adolescente, estuda a biologia dos ciborgues. Igualmente curioso é saber que, embora Rosie seja um modelo ultrapassado de doméstica-robô, a família não a substitui por motivos afetivos. Tal comportamento dos Jetsons, aliado a opiniões "humanizantes" de Rosie, conforme veremos, dão conta da suspeita de que haja algo de humano por trás, perdoem o lugar-comum, de sua armadura de lata.

Sabemos aquilo que desde o início foi proposto: Rosie constitui o retrato mais fiel do Outro. Ela o é absolutamente. Ser este Outro engloba ser, no caso de Rosie, mulher, negra e não humana. Este último termo, não humana, grafei-o assim propositalmente, de forma a dar margem para: a) discutirmos sua humanidade, e b) compreender que cargas semânticas injetamos no objeto que nomeamos "humano".

A questão se recoloca: Rosie é humana? Creio podermos cravar um intimorato "não" a esta questão. Mas em seguida perguntaríamos: Rosie é apenas um robô? Melhor: há, em Rosie, algo mais que um robô? A Biologia nos permitiria assentá-la como pertencendo, mesmo que parcialmente, à raça humana? E a Psicologia? A Robótica?

À primeira vista, para quem jamais viu Os Jetsons na tevê, a aparência de Rosie é de um robô. Entretanto, assistindo aos episódios, sobretudo o primeiro da série, o telespectador 
percebe que ela não é apenas um robô, mesmo que seja de uma versão já bastante ultrapassada.

Contudo, preliminar e esquematicamente aceitemos a suposição de Rosie ser um robô. Ora, se Rosie não é humana e é um robô, não há razão para trazermos à discussão a questão do ciborgue, que poderia ser compreendido como quando partimos a palavra: Cybernetic Organism. O ciborgue, portanto, mescla num mesmo corpo sua biologia humana a dispositivos cibernéticos. Rosie estaria preliminarmente de fora desta questão, pois não há indícios de que ela possua porções vivas em seu corpo.

Entretanto, de acordo com Donna Haraway, o ciborgue pode ser compreendido, além da caracterização de um misto de ser vivo e dispositivo, como "uma criatura de realidade social e também uma criatura de ficção" (HARAWAY, 2009, p. 36). Logo em seguida, a autora esclarece que entende "realidade social" como "relações sociais vividas, [...] nossa construção política mais importante, [...] uma ficção capaz de mudar o mundo" (Idem). Portanto, Haraway acaba por permitir a extensão do conceito para além do puramente biológico. O ciborgue não é apenas algo que conjumine o homem e a máquina, o natural e o fabricado, mas deve resultar num ser que se apresente e que tenha potência para ser representado socialmente. Vejamos a possibilidade de inserir Rosie como alternativa ciborgue a partir de um ponto de vista de interação, percepção e existência social. Para isso, analisemos o primeiro episódio da primeira temporada de Os Jetsons.

Em "Rosie, a robô"3(Os Jetsons: Rosie, a robô), Jane, a mamãe Jetson, vê-se (comicamente?) atribulada com seus afazeres domésticos. Aconselhada por sua mãe, Jane aluga (em uma promoção, pois o primeiro dia é gratuito) uma doméstica-robô. Na loja que aluga domésticas-robô, o seguinte diálogo, travado entre o vendedor, Rosie e Jane, faz a

\footnotetext{
${ }^{3}$ Aqui assinalamos sinopses de outros episódios igualmente interessantes, sendo que cada um mereceria um estudo exemplar à parte: 1) O namorado de Rosie: Henry, o zelador dos Jetsons, constrói um robô (Mac, feito a partir de restos: um arquivo de metal, uma chaleira, antigas chaves de fenda). O intento do zelador é que o robô o ajudasse em suas tarefas diárias. No seu primeiro encontro com Rosie, ambos se apaixonam. Concomitante a isso, Mac, transido pela paixão por Rosie, passa a cometer diversos equívocos, o que leva Henry a desativá-lo para que não the crie mais problemas. Após saber da desativação de Mac, Rosie passa a se comportar diferentemente, avoada, o que compromete a qualidade de seu serviço. Elroy é quem descobre que Rosie está diferente por estar longe de seu amado mecatrônico. Religado Mac, Rosie volta ao normal e o final feliz encerra o episódio; 2) Rosie, volte para casa: Com peças com prazo de funcionamento vencido, Rosie começa a apresentar defeitos em seu funcionamento. George e Jane saem à procura da peça a ser trocada. Equivocada pelo fato de seus patrões estarem numa loja de robôs, Rosie acha que os Jetsons não a querem mais, o que faz com que fuja de casa, antes de ser supostamente demitida. Depois de duas semanas sem Rosie e algumas peripécias, Judy acha Rosie perdida e a traz de volta para casa, onde sua peça é finalmente trocada. Volta a funcionar bem; 3) O dia das mães de Rosie: Rosie deseja conhecer sua mãe. A ligação com a mãe significa para ela a ligação com a própria memória, que à princípio é ligada a dispositivos e circuitos, não a neurônios unidos por um córtex; 4) Wedding bells for Rosie: Para Mac conseguir seu greencard e não ser desativado, precisa se casar.
} 
senhora Jetson optar pela robô, mesmo ultrapassada ("um velho modelo demonstrador com alta quilometragem", conforme descrita pelo vendedor):

VENDEDOR: A velha garota ainda é ávida ${ }^{4}$, não? Mas, claro, é muito I-N-C-U-LT-A.

ROSIE: Posso ser inculta, companheiro, mas sou E-S-P-E-R-T-A. Esperta.

JANE: Gostei dela, e vou levá-la.

(Os Jetsons, Episódio 1 - Rosie, a robô - falas retiradas das legendas)

Ressalte-se o viés de "inculto", igualmente presente no referido estereótipo da black Mammy. De qualquer forma, Rosie passa seu primeiro dia com a família e agrada irrestritamente. À noite, entretanto, Cosmo Spacely, patrão de George, chega como convidado para jantar. Depois da refeição, apreciada por todos, Rosie comete seu único pecado: discutir "petulantemente" com o patrão de seu patrão:

COSMO: Você tem uma empregada bastante eficiente, Jetson. (pausa) Empregada? Como consegue ter uma empregada com o que te pago?

GEORGE: Sabe, Sr. Sovina Mão-fechada... Digo, Sr. Spacely...

COSMO: Você tem um outro emprego, certo?

GEORGE: Não, senhor, eu...

COSMO: Está trabalhando à noite, não está? Admita.

ROSIE: Calma lá, baixinho.

COSMO: Não se meta nisso.

ROSIE: Escuta aqui, Sr. Spacely, esta gente é boa. Estão me dando esta chance pra eu não acabar virando sucata.

COSMO (virando-se de costas para ROSIE): Jetson, onde está meu chapéu?

ROSIE: Calma, rapaz, calma. É falta de modos deixar a mesa antes de comer a sua sobremesa (ROSIE enterra uma torta de abacaxi invertido na cabeça de COSMO). Agora, sim. Já inverti os abacaxis. Agora pode se mandar. Após mais uma coisa. Estas opiniões são minhas e não refletem a de meus empregadores.

(ROSIE sai)

(Os Jetsons, Episódio 1 - Rosie, a robô - falas retiradas das legendas)

Por conta do ocorrido, Rosie foi preliminarmente despedida por George, terminados a recepção e o jantar. Mais tarde, entretanto, ainda extasiado com a refeição, o Sr. Spacely liga para George e pede que reconsidere a demissão de Rosie. O episódio termina com a família acrescida da robô, seu novo membro.

Eles a "aceitam", tal qual aquele sujeito soberano europeu "aceita" seu outro: reduzindo-o (Tal redução assemelha-se ao esforço teórico para a construção de qualquer conceito científico). Nesse sentido, um movimento concomitante de subjetivação e objetivação paira sobre Rosie, pois se, por um lado, torna-se indispensável (tanto funcional quanto afetivamente) para a família a partir de então, ela, por sua aparente descartabilidade, assemelha-se mais a um objeto, dessubjetivando-se.

\footnotetext{
${ }^{4} \mathrm{Na}$ legenda original, consta: “The old girl's still eager, isn't she?”, o que remete a certa ansiedade de Rosie em ser adquirida/aceita por Jane Jetson. A legenda em português é de meados da década de 1960, o que pode explicar a aparente inadequação do termo "ávida". Entendamo-lo alternativamente como "ansiosa".
} 
O que primeiramente interessa é a forma com que Rosie encara sua demissão sumária, assumindo a culpa pelo próprio destempero (provocado por Spacely, ranzinza incorrigível).

\footnotetext{
JANE (vendo que Rosie se prepara para deixar a casa): Rosie, aonde você vai? ROSIE (Despedindo-se, após o jantar): Eu sei que vocês não têm condições de me ter aqui. Adeus, Srta. Judy, garoto Elroy... senhora e o senhor também.

ELROY: Rosie, não pode ir embora agora. Precisa me ensinar a dar um drible no basquete.

ROSIE: Não posso fazer nada, garoto Elroy. É assim que as coisas são. (fala para George) Desculpe por eu ter perdido a calma, senhor... mas o que se poderia esperar de um equipamento velho como eu? Bom, obrigada pela oportunidade. Ferro velho, aí vou eu. (ROSIE sai)

(Os Jetsons, Episódio 1 - Rosie, a robô - falas retiradas das legendas)
}

Neste ponto, vemos o sujeito hegemônico involuntariamente imiscuído no discurso do outro-Rosie, que concorda com o mascaramento em nome de sua aceitação naquele núcleo familiar hegemônico. Outro ponto de interesse é o maior paradoxo de Rosie nesse episódio: apesar de assumidamente subalterna e de permitir a inserção de outra lógica em seu discurso, a robô ousa e discute com o patrão do patrão, o que requer uma dose de autonomia impensada para um "outro" que deseja ser admitido como "um". Verga-se aos Jetsons, mas afirma-se como sujeito frente a Spacely, confrontando-o. Esse jogo de dissimulações, mesclado ao efeito encantatório de sua culinária, de certa forma impõe-se e a confirma como pertencente àquela família e, portanto, inserindo-se como realidade social, como o desejava Haraway.

Mas: apenas tal existência ou autonomia social, por si, bastaria para caracterizá-la como ciborgue, já que a própria Haraway atesta que a "fronteira entre a ficção científica e a realidade social é uma ilusão ótica" (HARAWAY, 2009, p. 36)? O conceito dá mesmo margem a hesitações, impondo-se como "recurso imaginativo que pode sugerir alguns frutíferos acoplamentos" (HARAWAY, 2009, p. 37). Ora, em verdade estamos diante de um conceito mais afeito à Filosofia (metafísica) que à Biologia, já que, inseridos num cenário topsecular de hibridismos e interações multidirecionadas, de tecnologias cercanas que ao mesmo tempo nos (a)condicionam e aprisionam, somos quimeras, seres híbridos que não podem mais prescindir dos artefatos tecnológicos que suplementam nosso corpo biológico.

\footnotetext{
um mundo de ciborgues pode significar realidades sociais e corporais vividas, nas quais as pessoas não temam sua estreita afinidade com animais e máquinas, que não temam identidades permanentemente parciais e posições contraditórias. (HARAWAY, 2009, p. 46)
}

Outro ponto importante, no que diz respeito à admissão de Rosie naquela alternativa ciborgue é apresentado por Haraway, ao afirmar que 
não tem qualquer fascínio por uma totalidade orgânica que pudesse ser obtida por meio da apropriação última de todos os poderes das respectivas partes, as quais se combinariam, então, em uma unidade maior. Em certo sentido, o ciborgue não é parte de qualquer narrativa que faça apelo a um estado original, de uma "narrativa de origem", no sentido ocidental. (HARAWAY, 2009, p. 38)

Desse modo, Rosie, se aqui admitida como ciborgue, não apenas se nega a trazer sua história, sua cultura e seus costumes: ela não os possui. Assim, adere fielmente àquele desejo do inconsciente hegemônico norte-americano do "outro": sem história, sem memória, sem narrativa, sem cultura. Se acrescemos o desprovimento à alteridade, temos um sujeito sem papel definido na história, sem ações afirmativas quanto ao papel que assume no processo da contemporaneidade, e, portanto, sem corporeidade social que o faça assomar como "um", permanecendo um "outro" inoperante porque inofensivo, invisível porque ahistórico.

Igualmente interessante é assinalar que este prescindir uma totalidade faz parte de um "pacote" conceituante do que se denomina contemporaneidade. É Giorgio Agamben quem afirma que a contemporaneidade é como a luz das estrelas dispostas nas fronteiras do universo: como o universo se expande a velocidade superior à da luz, a imagem daquelas estrelas jamais chegará à Terra:

Aquilo que percebemos como o escuro do céu é essa luz que viaja velocíssima até nós e, no entanto, não pode nos alcançar, porque as galáxias das quais provém se distanciam a uma velocidade superior àquela da luz [...] Perceber no escuro do presente essa luz que procura nos alcançar e não poder fazê-los, isso significa ser contemporâneo. (AGAMBEN, 2009, p. 65).

Assim, para o filósofo italiano, o presente da contemporaneidade tem "vértebras quebradas" (AGAMBEN, 2009, p. 65): não busca um passado que o figure ou conceba, tão assombrado está com o decifrar de si mesmo, presente irrepetível. Dessa forma, qualquer gesto na direção de uma totalidade se faz fraude.

Assim como as manifestações e tentativas de transformação social atuais prescindem de líderes, muitas vezes emergindo a própria multidão como o agente de per si das demandas postas, os processos contemporâneos de circulação cultural e simbólica não funcionam mais buscando mitos de origem que expliquem o presente no passado. $\mathrm{O}$ entendimento do presente é buscado nas forças que nele próprio atuam, o que torna o conceito de ciborgue (e sua negação a qualquer gesto de busca de um mito de origem) ainda mais aderente ao chamado "hodierno", e Rosie igualmente a ele aderente.

\section{A orelha de Van Gogh}

I've seen things you people wouldn't believe.

Attack ships on fire off the shoulder of Orion.

I watched c-beams glitter in the dark near the Tahhhäuser Gate. 
Como um resgate da última fala do replicante de Blade Runner antes de morrer, de que adianta toda a discussão em torno do que é denominado como alternativa ciborgue, em que supostos estereótipos redutores são suavizados, porque inseridos como alternativas de entendimento para um engendramento de dessemelhanças não só de fundo biológico, mas ontossimbólico; de que adiantam as discussões a respeito das dificuldades encontradas pelos chamados contradiscursos da modernidade em se instaurarem como possibilidade de entendimento/leitura do presente; ou de que adianta o paradoxo em que se deita o termo "subalterno", ao mesmo tempo gerado e nomeado por seu dominador, termo estendido mesmo até os limites da produção do conhecimento; de que adianta toda a discussão, todo o esforço teórico se não voltamos o olhar para a fundação cujos resultantes acabaram por exigir tamanho esforço de pensamento sobre essas questões? Aqui falamos do projeto da modernidade (ocidental, eurobranco) e suas exclusões. Aqui, o mito fundador de que Anderson (2008) fala ainda funciona como chave mestra para a compreensão, de dentro, daquele projeto de sociedade. Aqui, os movimentos erráticos de uma multidão ao mesmo tempo desidentificada e politizada são considerados mais como rebeldia e vandalismo do que exigência "séria" de transformação social. Tais componentes são, portanto, tidos como partes ou dispositivos indesejados ou ineficazes para o perfeito funcionamento do "sistema" da modernidade. O que nos leva, enfim, ao título do artigo.

Ensandecido e fora de si, o pintor Vincent Van Gogh corta parte da própria orelha. Este talvez seja o acontecimento mais ruidoso e famoso de toda a história da arte. Entretanto, apesar de até hoje ser envolvido em suspeitas (Quem a cortou, ele ou Gauguin? Deu-a a quem, a um estranho, a uma prostituta, a uma suposta amada?), ele pode nos ajudar a responder: o que personagens / espaços não pertencentes ao corolário de perfeição da modernidade significam para a própria modernidade? Ou: até que ponto a formação / criação desses personagens / espaços não foi decorrente da falência (ou percepção da fraudulência?) dos ideais da modernidade? Lembro o que todos sabemos: a modernidade formou-se no regaço do Renascimento e engordou graças aos úberes mornos do Iluminismo - portanto, está encharcada pelo canto das sereias oitocentista (liberdade, igualdade, fraternidade), reconhecido como inexequível pela história, espelho e vitrine da própria trajetória moderna ocidental.

Para auxiliar na ilustração do conceito, opto por algo ainda menos abstrato. Tomemos como exemplos de espaços de expressão de modernidades alternativas, periféricos 
à modernidade que são, qualquer uma das favelas espalhadas pelo mundo; e como exemplo de personagem (igualmente identificada com um modelo contradiscursivo de uma modernidade ocidental: humana, branca, culta e inserida na história), Rosie.

Tanto os espaços periféricos quanto os periféricos que habitam aqueles espaços se tratam de dejetos, de coisas impuras, de filhos defeituosos, de porções indesejadas da modernidade. Uma das cidades invisíveis (CALVINO, 2003), Leônia, serve à perfeição para ilustrar o travo amargo que os dejetos provocam ao projeto da modernidade.

\begin{abstract}
Nas calçadas, envoltos em límpidos sacos plásticos, os restos de Leônia de ontem aguardam a carroça do lixeiro. [...] O certo é que os lixeiros são acolhidos como anjos e sua tarefa de remover os restos da existência do dia anterior é circundada de um respeito silencioso, como um rito que inspira a devoção, ou talvez apenas porque, uma vez que as coisas são jogadas fora, ninguém mais quer pensar nelas. (CALVINO, 2003, p. 109)
\end{abstract}

Se a modernidade, encarnada numa pessoa, pudesse, escolheria decepá-los, tanto os espaços quanto as personagens; ela, a modernidade, tão transida pela própria miséria quanto aquele Vincent mais de dois séculos atrás. Esses dois contradiscursos são a orelha de Van Gogh: arranquêmo-la e, pure magie, a modernidade se purifica: formadora de seus monstros, deseja automutilar-se para alcançar o perpétuo. Quase que literalmente abre mão dos anéis para não perder os dedos. Da mesma forma, Rosie não é apenas Rosie (perdoem, mas o "a rosa é uma rosa" emergiu inexorável como imagem), mas encarna de modo semelhante a forma com que a modernidade enxerga qualquer tipo de dejeto criado por ela: garrafas pet, excrementos, Terceiro Mundo, refugiados, os loucos, os restos de guerra, os velhos, o lixo nuclear. Tais "coisas" e espaços são tão incômodos quanto a "diferente" Rosie.

Bill Ashcroft (2009) mais generosamente afirma que "a globalização pode ser caracterizada como uma multiplicidade de suas modernidades, e as teorias pós-coloniais podem oferecer um gesto de compreensão desse fenômeno" (p. 81): como no filme cult de sci-fi (Alien, o oitavo passageiro), um ser extraterrestre, amorfo e assustador, desentranha-se de um útero humano e branco, e, por origem, bem nascido. $\mathrm{O}$ grotesco emerge do belo: onde se origina um e termina o outro?

Rosie, portanto, auxilia a ratificar Ashcroft, para quem

\footnotetext{
pensar as modernidades alternativas, e aceitar que a modernidade não seja sinônimo de ocidentalização, é não abandonar o fato de a modernidade ser tanto uma época quanto um questionamento do presente, uma orientação para o futuro e ao mesmo tempo uma valoração ética do presente sobre o passado [...] a trajetória histórica da modernidade ocidental não se trata apenas de um signo de progresso temporal [...] mas um fenômeno culturalmente situado. (ASHCROFT, 2009, p. 83)
} 
Dessa forma, cabe questionar: o que emerge desses espaços e personagens emergentes alternativos? Que literatura ali nasce? Que formas de arte? Que processos identitários ali fluem e são constituídos, ou desmantelados? Quem sabe apenas uma ligação comunitária, além de uma identidade com o lugar, com a paisagem. Quem sabe seus limites não sejam mais demarcados espacialmente, mas com base em interações intersubjetivas cometidas nos intestinos dela mesma, perdoado o naturalismo exagerado do último trecho? $\mathrm{O}$ que interessa é que as demarcações identitárias não seriam mais espaciais, mas interacionais, implodindo as noções de comunidade imaginada, Estado e nação, reordenando o ponto de vista para enxergar tais espaços a partir dos movimentos de suas diversas subjetividades em interação. De qualquer forma, a subjetividade na pós-modernidade é a força motriz de qualquer coisa que se assemelhe a identidade cultural, porque está dispersa, foi dispersada dois, três séculos atrás, e reconstituída, só que com novas regras, em normas créole, blended, mezcladas.

\footnotetext{
Violentamente capturados e transportados, dispersos pelo Novo Mudo, colocados em plantations com falantes de diferentes línguas, destituídos não apenas de uma língua comum, mas de história e de origem, eles eventualmente conseguirão articular [constituir] sua [ideia de] modernidade pós-colonial. (ASHCROFT, 2009, p. 88)
}

Aqui o mundo se ajunta, sem as trilhas sonoras redentoras de última cena emocionante e o pôr-do-sol radioso, mas plasmado em suas contaminações, como propõe Silviano Santiago (2000, p. 16), mosaicado com as modernidades alternativas que, de dentro, vêm reinventando a modernidade tradicional ainda falsamente caiada sobre paredes cujos emboços aceitam desde grafites-arte a cartazes anunciando o ritmo que acalentará os quadris do próximo verão.

Desse ponto de vista pluriocular e esvaziado de afirmações monolíticas, o conceito de identidade perde seu caráter de produção de algo compartilhado por uma comunidade para produzir, pela adição das subjetividades que o compõem, humanas ou não, periféricas e hegemônicas, escritoras ou leitoras da própria história, um puzzle do desterro, um exílio de dessemelhantes.

\section{Referências}

AGAMBEN, Giorgio. O que é o contemporâneo? e outros ensaios. Chapecó-SC: Argos, 2009.

ANDERSON, Benedict. Comunidades imaginadas: reflexões sobre a origem e a difusão do nacionalismo. Trad. de Denise Bottmann. São Paulo: Companhia das letras, 2008. 
ASHCROFT, Bill. Alternative Modernities: globalization and the post-colonial. ARIEL: a review of international english literature, Baltimore, MD, Vol 40, $\mathrm{n}^{\circ}$ 1, p. 81-105, jan. 2009.

BAUMAN, Zygmunt. Vidas desperdiçadas. Trad. Carlos Alberto Medeiros. Rio de Janeiro: Zahar, 2005.

CALVINO, Italo. As cidades invisíveis. Trad. de Diogo Mainardi. São Paulo: Folha de São Paulo, 2003.

CLIFFORD, James. Travelling cultures. In: GROSSBERG et al. Cultural studies. London/New York: Routledge, 1992, p. 96-116.

FREYRE, Gilberto. Casa grande \& senzala: formação da família brasileira sob o regime da economia patriarcal. São Paulo: Global, 2003.

HARAWAY, Donna J. Manifesto ciborgue: Ciência, tecnologia e feminismo-socialista no final do século XX. In: Antropologia do ciborgue: as vertigens do pós-humano. Trad. de Tomaz Tadeu. Belo Horizonte: Autêntica, 2009, p. 35-118.

KOWALSKI, Jennifer. Stereotypes of History: Reconstructing Truth and the Black Mammy. Transcending silence, Albany, NY, Spring 2009 Issue. Disponível em http://www.albany.edu/womensstudies/journal/2009/kowalski/kowalski.html. Acesso em 15 jul. 2014.

SAID, Edward. Cultura e imperialismo. São Paulo: Companhia de bolso, 2011.

SANTIAGO, Silviano. Uma literatura nos trópicos. Rio de Janeiro: Rocco, 2000.

SPIVAK, Gayatri Chakravorty. Can the Subaltern Speak? In: NELSON, Cary; GROSSBERG, Lawrence. Marxism and the Interpretation of Culture. London: Macmillan, 1988, p. 24-28.

TORRES, Sonia. Nosotros in USA: literatura, etnografia e geografias de resistência. Rio de Janeiro: Zahar, 2001.

\section{Filmes}

Alien, o oitavo passageiro. Direção: Ridley Scott. 20th Century Fox, 1979. 1 DVD (117 min).

Blade Runner. Direção: Ridley Scott. Warner, 1982. 1 DVD (116 min).

E o vento levou. Direção: Victor Fleming. MGM, 1939. 1 DVD (238 min).

Os Jetsons: Rosie, a robô. Warner Bros, 1962. 1 DVD. EUA.

[Recebido em fevereiro de 2015 e aceito para publicação em junho de 2015]

Van Gogh's ear: Rosie and the alternative cyborg in "The Jetsons"

Abstract: Devoid of its history, and seeing her be redeemed only from the second half of the twentieth because of the growth of the movement of minority rights, both women and african American (and other minorities schematically untreated here) still difficult and demand 
understanding of efforts to act and are situated politically active mode in postmodernity. When something or someone focuses exclusion of those memorials (female and black) plus a non-humanity, can be considered exemplary "another" extreme. Rosie incarnate, so a US unconscious creator of the Third World migrants: an "other" no text, no speech, no history or culture. In this sense, its ontology is closely linked to its political insertion relative to that society - subordinate (SPIVAK, 1988), peripheral and alternative. At the same time symbolically sting a slave past and a present of latent prejudices [image Black Mammy (KOWALSKI, 2009) is symptomatic of this trend and will also be treated here] and the social unpaid debts, points to a possible future convergences alternatives, both racial and ethical as (bio) policies. His power and his weakness share the same space. As the literature understood as peripheral or border constantly generate excesses in that geography melts and runs counter to the ontology, with the subjectivities put in check, and the historical development as background, we can understand that Rosie figure as a kind anti-Barbie mechatronics. Thus, from the Rosie character, the domestic robot television series The Jetsons, the paper reflects on the struggles of the peripheral subject (because non-male, non-white, non-religious and non-human) inserted in modernity. By articulating concepts such as cyborg and subordination, and stereotypes like the black Mammy, will seek to glimpse the presence of a hegemonic contradiscursivity embodied by Rosie, biotipicamente identified with the standard negroid and understood as devoid of the right to national history, a myth founder and a way of narrating the past itself. From this point of view, Rosie emerges as representative of alternative modernities present within the project of modernity.

Keywords: Contradiscursivity. Alternative modernities. Cyborg. Black Mammy.

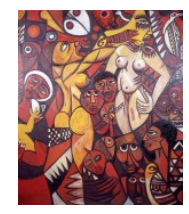

